\title{
DEMOCRACIA Y SOCIALISMO: EL FUTURO ENRAIZADO EN EL PRESENTE
}

Marta Harnecker*

\section{Resumen}

La democracia liberal representativa es presentada como la única y verdadera democracia. Además de que, en su nombre, se invaden territorios y sacrifican pueblos enteros, la voluntad popular no se expresa libremente en las urnas y, en última instancia, el pueblo no es quien gobierna. No es suficiente otorgar un sentido social a la democracia liberal —al atender, por ejemplo, problemas como alimentación, salud y educación-, sino que el desafío es que los pueblos rescaten la política para instalar un democracia verdadera donde las personas, al luchar por cambiar las circunstancias, se transformen a sí mismas. Dada la injusticia y desigualdad predominantes, hablar hoy de socialismo tiene sentido. No se trata de copiar modelos foráneos o de exportar el nuestro, sino de transformar la economía, instalar la democracia participativa y consolidar una ética solidaria e igualitaria para construir el socialismo en cada país. La participación popular y las redes de democracia directa son el fundamento para el desarrollo humano socialista.

Palabras clave: democracia liberal, democracia directa, socialismo, desarrollo humano, participación popular.

* Socióloga y autora de textos de divulgación y análisis del pensamiento de la izquierda marxista y asesora de gobiernos progresistas latinoamericanos. 


\begin{abstract}
Liberal representative democracy is presented as the only real democracy. Moreover, in its name, territories are invaded and entire peoples are sacrificed, the popular will is not freely expressed in the ballot box, and ultimately the people do not govern. It is not sufficient to assign social meaning to liberal democracy — to pay attention, for example, to problems like food, health and education-, the challenge, rather, is for ordinary people to rescue politics in order to install an authentic democracy, one in which people transform themselves while fighting to change circumstances. Given the predominance of injustice and inequality, it makes sense today to talk of socialism. It's not about copying foreign models or exporting ours, but rather about transforming the economy, installing participatory democracy, and consolidating the ethics of solidarity and equality in order to construct socialism in each country. Popular participation and the networks of direct democracy are the basis for socialist human development.
\end{abstract}

Keywords: liberal democracy, direct democracy, socialism, human development and popular participation. 


\title{
INTRODUCCIÓN
}

\begin{abstract}
omienzo por mencionar tres factores que influyeron en la maduración de mi pensamiento sobre el socialismo del siglo XX y del socialismo por reconstruir en el siglo XXI: a) la visión pedagógica del brasileño Paulo Freire, que dio origen a un significativo movimiento de educación popular en varios de nuestros países, que chocaba con la concepción clásica de los partidos de izquierda de aquella época que solían considerarse dueños de la verdad; $b$ ) las ideas feministas que ponían el acento en el respeto a las diferencias y en el rechazo al autoritarismo; c) el proyecto liderado por el presidente de Venezuela Hugo Chávez de avanzar hacia la construcción del «socialismo del siglo XXI», término acuñado por él para diferenciarlo de los errores y desviaciones del llamado «socialismo real» del siglo XX en la Unión Soviética y los países del Este europeo. La lección principal del proyecto chavista es la necesidad e importancia de combinar el socialismo con la democracia, no una democtracia liberal, sino una democracia participativa y directa. ${ }^{1}$
\end{abstract}

\section{FALACIAS DE LA DEMOCRACIA LIBERAL REPRESENTATIVA}

Antes de entrar en el tema de la relación entre democracia y socialismo, plantearé algunas falacias de la democracia liberal o representative, que se presenta ante el mundo como la única y verdadera democracia, y a nombre de la cual se invaden territorios y se sacrifica a pueblos enteros.

1 A propósito, Chávez señala como elementos fundamentales del socialismo del siglo XXI la «transformación económica», la «democracia participativa y protagónica en lo político» y, con referencia al pensamiento del Che Guevara, «la ética socialista: el amor, la solidaridad, la igualdad entre los hombres, las mujeres entre todos». Para Chávez, el socialismo debe ser un régimen esencialmente democrático y adaptado a cada realidad nacional. 
La voluntad popular no se expresa libremente a través de las urnas

Se sostiene que la democracia expresa la voluntad del pueblo y que esta voluntad se expresa a través de las urnas. ${ }^{2}$ Pero, ¿ podemos afirmar que en todos los casos el resultado electoral refleja la voluntad popular? ¿Tiene el pueblo la capacidad de elegir con criterio independiente a sus representantes si la información con la que cuenta es inadecuada o insuficiente en el momento de votar? Al respecto, debemos recordar las palabras de Aristóbulo Istúriz, ex ministro de Educación del gobierno bolivariano de Venezuela: «sólo existe democracia con gente igualmente informada» (Harnecker, 1994).

Cuando Aristóbulo Istúriz fue alcalde de Caracas, trató de hacer una gestión muy participativa y se encontró con el problema de cómo llegar a la gente, cómo acercar hasta al más humilde de los ciudadanos la posibilidad de politizarse y de adquirir la capacidad para tomar decisiones. Para lograr eso, era fundamental darle información a la gente.

Nosotros creemos que la democracia representativa nuestra no es nada democrática; creemos que es la negación de la democracia: niega al ciudadano. Lo que estamos viviendo es una consecuencia, es una herencia de la ausencia de la democracia. Por eso no tenemos ciudadanos. ¿Qué ciudadanos pueden existir en una democracia representativa como ésta? En una democracia de este tipo no pueden existir ciudadanos. ¿Por qué?, porque sólo existen ciudadanos cuando hay igualdad de información entre ellos. Eso es democracia. Mientras más información tenga la gente, mejor, porque la democracia es la capacidad de tomar decisiones de manera libre, y para tomar decisiones en estas condicio-

2 Según la Declaración Universal de los Derechos Humanos aprobada en Asamblea de las Naciones Unidas el 10 de diciembre de 1948, la voluntad del pueblo debe ser la base de la autoridad del gobierno. La declaración dice textualmente: Artículo 211 «Toda persona tiene derecho a participar en el gobierno de su país, directamente o por medio de representantes libremente escogidos. [...] 3. La voluntad del pueblo es la base de la autoridad del poder público; esta voluntad se expresará mediante elecciones auténticas que habrán de celebrarse periódicamente, por sufragio universal e igual y por voto secreto u otro procedimiento equivalente que garantice la libertad del voto». 
nes yo tengo que tener información, si no tengo la información participo en desventaja y soy manipulado (Harnecker, 1994: 1226).

¿Puede alguien honestamente afirmar que los ciudadanos y las ciudadanas de nuestros países están igualmente informados? ¿Puede sostenerse que los medios de comunicación son medios que informan objetivamente de la realidad? ¿Qué objetividad de información puede existir cuando las grandes cadenas televisivas nacionales y transnacionales silencian procesos, levantan caudillos, seleccionan la información que les es funcional y eliminan la que los perjudica? Hay miles de ejemplos al respecto.

Señalaremos solamente uno: la campaña para hacer creer que Venezuela está en una carrera armamentista que amenaza la región. Esta campaña se apoya en la reciente compra de armamento a Rusia por este país. Pero, si se consultan datos de la CIA, se comprueba que la situación es muy diferente. Partiendo de esos datos, el economista belga, Eric Toussaint, informa:

El gasto militar venezolano es el sexto de la región en orden de importancia, viene después de Brasil, de Argentina, de Chile (un país mucho menos poblado que Venezuela y considerado como modelo), de Colombia y de México. En términos relativos, referido al producto interno bruto de cada país, el presupuesto militar venezolano ocupa el noveno lugar en América Latina. ¿Se ha podido leer esto en la gran prensa? Por el contrario, sí se pudo leer en agosto del 2009 que Suecia pedía cuentas a Venezuela porque el gobierno colombiano había denunciado que su vecino era proveedor de armas a la guerrilla de las FARC. Y Suecia había en efecto declarado a Colombia que misiles SAAB encontrados en un campo de las FARC habían sido provistos por este país a Venezuela. ¿Pero quién pudo leer la respuesta detallada y concisa dada por Hugo Chávez? Los misiles en cuestión habían sido robados de un puerto venezolano en 1995, cuatro años antes que Chávez accediera a la presidencia la República (Toussaint, 2009).

Sabemos que solamente una condición ponen los liberales burgueses para aceptar el juego democrático: que puedan, como afirma 
Chomsky (1996), domesticar al rebaño perplejo controlando los medios para fabricar el consenso. Y ya sabemos que, de resultar ineficaces los mecanismos para fabricar el consenso, se recurre, donde es posible, a métodos antidemocráticos: promover separatismo, impulsar golpes institucionales con apoyo militar, etcétera.

\section{No es el pueblo el que gobierna}

Pero no solamente la gente no está igualmente informada y, por lo tanto, difícilmente puede decidir en forma fundamentada, sino que la democracia liberal burguesa representativa reduce la democracia al acto de votar cada equis cantidad de años.

El pueblo deja de existir como un conjunto de ciudadanos interesados en lo público; el sujeto se limita a ser un ciudadano que vota, de ahí la consigna: ¡Un hombre, un voto! La esfera de la política está alejada de las responsabilidades directas de los electores, su única responsabilidad está en elegir cada cierto tiempo a representantes para que asuman las tareas políticas. Como dice el ex alcalde venezolano de Caroní, Clemente Scotto, «La política [ha sido] sustraída del ejercicio cotidiano de la gente y ha sido arrebatada por un sector que se llama a sí mismo "profesional de la política" y que, en definitiva, es el único que se siente con derecho a opinar (Harnecker, 1994: 179).

Los grandes problemas nacionales no son debatidos por las ciudadanas y los ciudadanos. Las decisiones sobre el destino del ingreso de los productos estratégicos, sobre qué actitud adoptar frente a la deuda externa, y otros temas, han sido tomadas siempre por esos profesionales de la política.

En la democracia liberal representativa no es el pueblo el protagonista de la democracia, ni siquiera lo son los representantes electos por «voto popular»; los verdaderos protagonistas están tras bambalinas y son unos pocos grupos de interés muy poderosos. Por eso algunos han calificado de «oligárquica» esta democracia. Como sostiene Luis Tapia (2007: 124), si queremos hablar de democracia, hay que «desmonopolizar la política». 


\section{Ir hacia el rescate de la política}

Debemos ir hacia el rescate del ejercicio de la política por nuestros pueblos, hacia una democracia verdadera, ir hacia un auténtico protagonismo popular.

Para hablar de representación hay que hablar, a la vez, de participación política. Se podría decir que hay representación democrática sólo en relación a un momento y a un tiempo de participación colectiva amplia. Se enuncia como representación algo que en rigor es sustitución, ya que los procesos electorales a través de los cuales se elige a los llamados representantes están desligados de momentos de deliberación que produzcan el contenido de esa representación. Lo que uno elige es quién va a sustituir a los ciudadanos, por un tiempo, en las tareas ya sean ejecutivas o legislativas, en funciones de gobierno estatal, ya sea a nivel municipal o a nivel del gobierno central o nacional. Lo que el representante hace luego de ser elegido puede no tener relación con los ciudadanos que votaron por él, en el sentido de que no hay un espacio en el que éstos puedan, a través de su participación, alimentar con opiniones políticas al supuesto representante. Antes de elegir o diseñar las instituciones de selección de los representantes, hay que pensar en los espacios y las formas de participación u organización de la vida política, que luego se podría y se necesitaría representar en niveles de articulación mayor a aquellos en los que puede haber efectivamente participación amplia de todo los ciudadanos que sí quieran hacerlo (Tapia, 2007: 126-127).

Por eso es que no podemos pensar que se pueden corregir las debilidades de la democracia liberal representativa otorgándole un sentido social a la democracia.

\section{No basta con otorgar sentido social a la democracia liberal}

No se trata solamente, como decía Alfredo Maneiro, intelectual y dirigente político venezolano, «de otorgar un contenido social a la forma democrática», de resolver los problemas sociales del pueblo (alimentación, salud, educación, etcetera), sino de «una 
reformulación de la forma democrática misma» (Maneiro, 1977: 207) que permita crear espacios para que las personas, al luchar por el cambio de las circunstancias, se vayan transformando a sí mismas. No es lo mismo, decía Maneiro, que una comunidad conquiste una pasarela para lo cual se ha organizado y ha luchado, a que reciba la pasarela como un regalo del Estado paternalista. La conquista de la pasarela dejó además en quienes lucharon por ella «algo inapreciable, no cuantificable(...): dejó auto confianza popular, la gente sabe que luchando consigue, pero que debe luchar» (Maneiro, 1977: 212-213).

El paternalismo de Estado es incompatible con el protagonismo popular. Conduce a transformar a la gente en mendigos. Hay que pasar de la cultura del ciudadano que mendiga a la cultura del ciudadano que conquista, que toma decisiones, que ejecuta y controla, que autogestiona, que autogobierna. Hay que pasar, como dice Aristóbulo Istúriz, del gobierno para el pueblo al autogobierno del pueblo, a que el pueblo asuma el poder. Y esto solamente puede ocurrir donde reina una democracia plena, socialista.

\section{SOCIALISMO Y DEMOCRACIA}

\section{Por qué hablar de socialismo}

Por qué hablar de socialismo, podríamos preguntarnos, si esa palabra ha tenido y sigue teniendo una carga negativa tan grande luego del derrumbe del socialismo en la Unión de Repúblicas Soviéticas Socalistas (URSS) y en el resto de los países de Europa del Este. Durante varios años después de que desapareciera el socialismo soviético, los intelectuales y las fuerzas progresistas hablaron más de lo que el socialismo no debía ser que del modelo que se quería construir. Entre los aspectos que se rechazaban -con razón-, están los siguientes: el estatismo, el capitalismo de Estado, el totalitarismo, la planificación central burocrática, el colectivismo que pretendía homogeneizar sin respetar las diferencias, el 
productivismo que enfatizaba en el avance de las fuerzas productivas sin tener en cuenta la necesidad de preservar la naturaleza, el dogmatismo, el ateísmo, la necesidad de un partido único para conducir el proceso de transición.

Hay una razón muy poderosa para hablar de socialismo: quisiera citar al vicepresidente de Bolivia, Álvaro García Linera, que en palabras muy sencillas lo explicaba a su pueblo el 8 de febrero de 2010, a un año de promulgada la nueva Constitución de Bolivia; refiriéndose a lo que denominó «socialismo comunitario», dijo entonces: «Estamos hablando de este tema por un solo motivo: porque la sociedad que hoy existe en el mundo, la sociedad que hoy tenemos en todo el planeta, es una sociedad con demasiadas injusticias, una sociedad con demasiadas desigualdades». Siguió con un argumento que resumimos en los próximos términos:

Hoy en este mundo capitalista en el que estamos viviendo (...) al año se mueren 11 millones de niños por desnutrición, por mala atención médica, porque no tienen el apoyo para curar enfermedades curables (...) Es como si toda la población de Bolivia se muriera cada año, cada año y cada año./ Esta sociedad capitalista que domina en el mundo, que nos da vuelos espaciales, que nos da Internet, permite que cada noche se duerman con hambre 800 millones de humanos. En el mundo hay cerca de dos mil millones de personas que no tienen servicios básicos. Tenemos carros, tenemos aviones, estamos pensando en ir ahora a Marte, ¡excelente!, pero en casa hay personas que se mueren de hambre, hay personas que no tienen servicios básicos, hay personas que no tienen educación y, por si fuera poco, esta es una sociedad que permanente y recurrentemente genera muchas crisis y las crisis generan desempleos, cierre de empresas. Hay tanta riqueza pero concentrada en pocas manos y mucha gente que no tiene y no puede disfrutar de esa riqueza. Hoy en el mundo hay 200 millones de desocupados./ Este es el problema, es una sociedad que genera demasiadas contradicciones que despliega conocimientos, ciencia y riqueza, pero que a la vez genera demasiada desigualdad, demasiada pobreza, demasiado abandono y, por si fuera poco, no se contenta con destruir al ser humanos, sino que también destruye la naturaleza. Miles de especies de animales, de plantas, han 
sido aniquiladas en los últimos 400-500 años desde la historia del capitalismo. Los bosques se van empequeñeciendo, se debilita la capa de ozono, hay un cambio climático, nuestros cerros con nevados eternos están desapareciendo./ Cuando uno habla del socialismo está hablando de algo que sea distinto a lo que estamos viviendo. Podemos colocarle otro nombre. Si a alguien no le gusta la palabra socialismo que le coloque «comunitarismo», si no le gusta comunitarismo, que le coloque el nombre de «buen vivir», no hay ningún problema, no nos vamos a pelear por los nombres (García, 2010).

Como se sabe, Hugo Chávez pensó en un comienzo que podía avanzar en las transformaciones sociales sin tocar el capitalismo, por una tercera vía, ${ }^{3}$ pero muy pronto se dio cuenta de que esto no era posible. La oligarquía venezolana no estuvo dispuesta a ceder en nada; apenas se vio afectada levemente en sus intereses por las leyes habilitantes que se dictaron a fines del 2001, organizó un golpe de Estado; una vez fracasado este plan, trató de paralizar el país saboteando especialmente la producción de petróleo. Esta experiencia, junto con la constatación de que desde el aparato de Estado burgués heredado no se podían atender con la rapidez requerida los angustiosos problemas de su pueblo, y que, «en el marco del modelo capitalista, es imposible solucionar el drama de la pobreza, es imposible solucionar el drama de la miseria, de la desigualdad, hicieron que el líder bolivariano se convenciera que había que buscar otro camino; avanzar hacia una sociedad diferente, hacia lo que denominó "socialismo del siglo XXI"» (Chávez, 2005).4

3 «Algunos hablan y han escrito mucho de la tercera vía, capitalismo con rostro humano, capitalismo renano, capitalismo marciano y no sé cuántos, tratando de poner una careta al monstruo; pero careta que le ponen al monstruo careta que cae al suelo destrozada por la realidad. Yo mismo debo confesarlo, no hace falta confesarlo, lo saben sobre todo los venezolanos, estuve transitando una época y haciendo referencias a la tercera vía»(Chávez, Discurso en la IV Cumbre de la Deuda Social, 25 de febrero de 2005).

4 Otros autores han preferido denominarlo «socialismo para el siglo XXI», entre ellos, Michael Lebowitz. 


\section{Un socialismo que no es calco ni copia, enraizado en nuestra historia}

Pero no se trata de copiar modelos foráneos ni de exportar el nuestro, se trata de construir un modelo de socialismo adaptado a cada país. Por supuesto, compartiendo algunos rasgos que son los que dan el carácter socialista a nuestra construcción, entre ellos, la transformación económica, la democracia participativa y protagónica en lo político, la ética socialista «basada en el amor, la solidaridad, la igualdad entre los hombres, las mujeres» (Chávez, 2006: 41). Estas ideas y valores socialistas son muy antiguos. Ya se encuentran, según el líder bolivariano, en los textos bíblicos, ${ }^{5}$ en el Evangelio, ${ }^{6}$ en las prácticas de nuestros aborígenes.

Chávez piensa - como Mariátegui- que el socialismo del Siglo XXI no puede ser «calco y copia», sino que debe ser «creación heroica», por eso habla de un «socialismo bolivariano, cristiano, robinsoniano, ${ }^{7}$ indoamericano». Se trata de «una nueva existencia colectiva, de la igualdad, de la libertad, de la democracia verdadera y profunda» (Chávez, 2006: 51).

Chávez coincide con el pensador peruano en que una de las raíces fundamentales de nuestro proyecto de socialismo se encuentra en el socialismo de nuestros aborígenes, por eso plantea que hay que rescatar y potenciar las prácticas indígenas imbuidas de espíritu socialista.

Por su parte, cuando en Bolivia se habla de «socialismo comunitario» se está apuntando a rescatar lo que el vicepresidente de la República ha denominado:

la civilización comunal, con sus procedimientos tecnológicos fundados en la fuerza de masa, en la gestión de la tierra familiar y comunal, en la fusión entre actividad económica y política, con sus propias autoridades e instituciones políticas, que privilegian la acción normativa sobre

5 El profeta Isaías, junto a muchos otros profetas, trajo un mensaje de igualdad, de claro espíritu socialista. (Chávez, 2006: 42).

6 Cita la versión original del «Sermón de la montaña» que aparece en el Evangelio de San Lucas (Chávez, 2006: 42-43).

7 Se refiere a Simón Rodríguez, maestro y amigo de Bolívar, a quien llamaba Robinson. 
la electiva y en la que la individualidad es un producto de la colectividad y su historia pasada (García, 2007: 46). ${ }^{8}$

Según García Linera, la mayoría de la población boliviana:

está sumergida en estructuras económicas, cognitivas y culturales no industriales y detentadoras, además de otras identidades culturales y lingüísticas [siendo portadora] de otros hábitos y técnicas políticas resultantes de su propia vida material y técnica: La sobreposición de la identidad colectiva por encima de la individualidad, la práctica deliberativa por encima de la electiva, la coerción normativa como modo de comportamiento gratificable por encima de la libre adscripción y cumplimiento, la despersonalización del poder, su revocabilidad consensual, la rotatividad de funciones, etcétera, son formas de comportamiento que hablan de culturas políticas diferenciadas de las liberales y representativas partidarias (García, 2007: 48).

Constar estas realidades debería llevarnos a despojarnos de la cultura paternalista occidental que piensa que debemos ir a ayudar a las comunidades indígenas. Chávez sostiene que más bien deberíamos pedirles ayuda «para que cooperen con nosotros en la construcción del proyecto socialista del siglo XXI» (Chávez, 2006: 48).

\section{Una sociedad socialista esencialmente democrática}

Chávez ha insistido en el carácter fundamentalmente democrático del socialismo del siglo XXI, advirtiendo que no debemos «caer en los errores del pasado», en la «desviación estalinista» que burocratizó al partido y terminó por eliminar el protagonismo popular.

$8 \mathrm{El}$ investigador boliviano distingue cuatro regímenes civilizatorios en Bolivia: el primero es el moderno mercantil industrial, el segundo lo constituye la economía y la cultura organizadas en torno de la actividad mercantil simple de tipo doméstico, artesanal o campesina (esta actividad constituye el 68\% del empleo urbano), un tercer régimen civilizatorio es a la civilización comunal y, por último, está la civilización amazónica, basada en el carácter itinerante de su actividad productiva, la técnica basada en el conocimiento y laboriosidad individual y la ausencia de estado». En conjunto, las dos terceras partes los habitantes del país se hayan en alguna de las tres últimas «franjas civilizatorias o societales» (García, 2007: 46-47). 
La negativa experiencia práctica del socialismo real en el terreno político no puede hacernos olvidar que, en el planteamiento de los clásicos del marxismo, la sociedad alternativa al capitalismo estuvo siempre asociada a la democracia plena. Marx y algunos de sus seguidores la denominaron "comunismo» y otros la han llamado «socialismo». Coincido con Álvaro García Linera en que el término que se use poco importa, lo importante es su contenido.

Pocos conocen un pequeño texto de Lenin acerca del Estado que contiene notas previas a su libro El Estado y la Revolución, donde sostiene que el socialismo debe concebirse como la sociedad más democrática, a diferencia de la sociedad burguesa, que es democrática solamente para una minoría. Haciendo una comparación con el capitalismo, el dirigente bolchevique afirma que, en este régimen, solamente existe democracia para los ricos y para una pequeña capa del proletariado, mientras que, en la fase de transición o socialismo, la democracia es casi completa, y no es completa porque no puede desconocer la voluntad de la mayoría y debe imponerla sobre quienes no quieren someterse a esa voluntad mayoritaria y que, una vez alcanzada la sociedad comunista, la democracia sería efectivamente completa (Lenin, 1980).

Esa visión estaba inspirada en los planteamientos de Marx y Engels, para quienes, la futura sociedad permitiría el pleno desarrollo de todas las potencialidades del ser humano. Los seres humanos fragmentados que el capitalismo produce serían reemplazados por seres humanos plenamente desarrollados. Se trata, como decía Friedrich Engels:

en su primer borrador del Manifiesto comunista de 'Organizar la sociedad de tal manera que cada uno de sus miembros pueda desarrollar y utilizar su potencial y sus facultades en completa libertad y, por lo tanto, sin desnaturalizar la esencia básica de esa sociedad'. En la versión final de Marx del Manifiesto, esa nueva sociedad se presenta como una 'asociación en que el libre desarrollo de cada uno sea la condición del libre desarrollo de todos» (Lebowitz, 2006: 17). 
El punto de partida: la persona humana como ser social, respeto por las diferencias

Como podemos ver, en el pensamiento de Marx y Engels hay una relación entre el «uno» y el «todos», porque el punto de partida del socialismo del siglo XXI es la persona humana como ser social. Nuestra concepción socialista no parte, como lo hace el capitalismo, de la persona como ser individual, de la persona aislada, separada de las demás, sino de la persona que únicamente puede desarrollarse a sí misma si se desarrolla junto a otras.

No existe el ciudadano abstracto, como dice el filósofo francés Henry Lefebvre, alguien que está por encima de todo, que no es ni rico ni pobre, ni viejo ni joven, ni macho ni hembra o lo es todo a la vez. Como escribe el yugoslavo Miodrag Zecevic: «Lo que existe son personas concretas que viven y dependen de otras personas, que se asocian y organizan de diferentes maneras con otras personas en comunidades y organizaciones en las cuales y por medio de las cuales realizan sus intereses, sus derechos y sus deberes» (Zecevic, 1977).

Por eso, autogobernarse implica:

cogobernar con otros. Diseñar una forma de gobierno democrático implica, entonces, pensar un conjunto de espacios, de procesos, de procedimientos a través de los cuales las personas puedan autogobernarse cogobernando con otros. Por eso, lo democrático no estaría definido [por] el procedimiento de elección y selección de gobernantes, sino [por la forma en que] se articulan y complementan el conjunto de instituciones, procedimientos y principios que organizan el conjunto de la vida social (Tapia, 2007: 123).

Me parece importante aclarar que, cuando se postula como base filosófica de la democracia socialista que la persona humana es un ser social, no se está planteando la negación del individuo, lo que se afirma es que la naturaleza humana individual es eminentemente social y que, al desarrollar valores sociales, como la solidaridad, se 
está desarrollando más plenamente el individuo. Hay una relación dialéctica complementaria entre el ser individual y el ser social que imposibilita que en el ser humano se pueda establecer una separación de su carácter individual y su entorno social. Por lo tanto, esta concepción nada tiene que ver con la desviación «colectivista» del socialismo del siglo $\mathrm{XX}$, aquel enfoque que suprimía las diferencias entre los miembros de la sociedad en nombre de un colectivo uniforme. El colectivismo es una fragante deformación del marxismo. Basta recordar que Marx criticaba el derecho burgués por pretender igualar artificialmente a los hombres en lugar de reconocer sus diferencias y por eso sostenía que una distribución verdaderamente justa tenía que tener en cuenta las necesidades diferenciadas de las personas. De ahí su máxima: «De cada cual según su trabajo, a cada cual según sus necesidades».

\section{Democracia y protagonismo popular}

Hemos hablado de «pleno desarrollo humano», pero ¿cómo se alcanza? Michael Lebowitz sostiene que solamente «una democracia revolucionaria puede crear las condiciones en las que podemos diariamente inventarnos a nosotros mismos como seres humanos ricos». El autor se refiere al «concepto de democracia en la práctica, democracia como práctica, democracia como protagonismo». La democracia en este sentido: «democracia protagónica en el lugar de trabajo, democracia protagónica en los barrios, en las comunidades, en los municipios, es la democracia del pueblo que se transforma a sí mismo en sujeto revolucionario» (Lebowitz, 2008: 56).

La necesidad del protagonismo popular es un tema recurrente en las intervenciones del presidente venezolano y es un elemento que lo distancia de muchos defensores del socialismo democrático. En el primer programa radio-televisivo de carácter más teórico (Primer Aló teórico), el 11 de junio de 2009, citó extensamente una carta que Pedro Kropotkin escribió a Lenin el 4 de marzo de 1920. Creo importante señalar aquí las ideas más importantes leídas por Chávez, porque revelan las preocupaciones del líder bolivariano: 
Sin la participación de fuerzas locales, sin una organización de las fuerzas desde abajo, de los campesinos y de los trabajadores, por ellos mismos, es imposible el construir una nueva vida. Pareció que los soviets iban a servir precisamente para cumplir esta función de crear una organización desde abajo. Pero Rusia se ha convertido en una República Soviética sólo de nombre (...) la influencia del partido sobre la gente (...) ha destruido ya la influencia de energía constructiva que tenían los soviets, esa promisoria institución. En el momento actual, son los comités del «Partido», y no lo soviets, quienes llevan la dirección en Rusia, y su organización sufre los efectos de toda organización burocrática. (Chávez, 11 de junio de 2009).

\section{El desarrollo humano a través de la participación popular}

La participación en todos los espacios es lo que permite al hombre crecer, ganar en confianza, es decir, desarrollarse humanamente.

La Constitución bolivariana - aprobada por la Asamblea Constituyente en 1999- pone énfasis en la participación popular en los asuntos públicos y subraya que es este protagonismo el que va a garantizar el pleno desarrollo, tanto de la persona como del colectivo. Aunque hay varios artículos de la Constitución que se refieren a este tema, probablemente el más completo es el artículo 62, donde se señala la forma en que este desarrollo se logra. Allí se dice que la «participación del pueblo en la formación, ejecución y control de la gestión pública es el medio necesario para lograr el protagonismo que garantice su completo desarrollo, tanto individual como colectivo», señalándose a continuación que es «obligación del Estado y deber de la sociedad facilitar la generación de las condiciones más favorables para su práctica» (Asamblea Nacional Constituyente, 1999). Además, el artículo 70 señala otras formas que permiten al pueblo desarrollar sus capacidades y habilidades: «la autogestión, cooperativas en todas sus formas (...) y demás formas asociativas guiadas por los valores de la mutua cooperación y la solidaridad» (Asamblea Nacional Constituyente, 1999: 31). ${ }^{9}$

9 Ley del poder público municipal, Art. 234, 17 mayo de 2005. 32. Ibid, Art. 33. 33. En Venezuela los municipios están divididos en parroquias.

166

ESTUDIOS CRÍTICOS DEL DESARROLLO, VOL. I, NO. 1 
En el terreno de la participación territorial local se ha insistido en los procesos de diagnóstico participativo, presupuesto participativo y de la contraloría social. Se creó inicialmente la figura de los consejos locales de planificación pública (CLPP) a nivel municipal, con representación institucional (alcaldes, concejales, miembros de las juntas parroquiales) y representantes de las comunidades para llevar adelante estas tareas. Es importante hacer notar que la representación de las comunidades tiene más peso que la institucional (51\% contra 49\%) reflejando la clara voluntad política de estimular el protagonismo de aquellas.

\section{Crear espacios adecuados para la participación}

Pero si somos coherentes, no basta que insistamos en la importancia del protagonismo popular, debemos impulsar la creación de espacios adecuados para que puedan darse plenamente los procesos participativos, pues en el horizonte de la democracia liberal burguesa no está la creación de estos espacios; por el contrario, lo que plantea es elegir representantes que, como ya señalamos, de hecho sustituyen a las ciudadanas y ciudadanos en los procesos de deliberación y toma de decisiones.

Coincido plenamente con el investigador boliviano Luis Tapia en que es necesario diseñar un conjunto de espacios en los que la presencia de las ciudadanas y los ciudadanos no sea esporádica sino continua, es decir, que tengan «la posibilidad de ejercer el derecho de cogobernar junto a sus otros conciudadanos tanto a nivel local como nacional (....) Para poder salir de este desorden mantenido, Rusia debe retomar todo el genio creativo de las fuerzas locales de cada comunidad». Según él, un régimen sería más democrático en la medida en que permitiera «crear las condiciones para que durante más tiempo y de manera más continua, es decir, en más espacios» pueda darse el protagonismo popular tanto individual como colectivo (Tapia, 2007: 124; Marx, 1977).

Solamente si se crea una sociedad basada en la autogestión de los trabajadores en sus centros de trabajo y en las comunidades 
donde habitan, el Estado dejará de ser un instrumento por encima del pueblo al servicio de unas élites, para transformarse en un Estado conformado por las mejores mujeres y hombres del pueblo trabajador, por eso es tan importante la iniciativa del presidente Chávez de crear los consejos comunales y, más tarde, su propuesta de crear consejos de trabajadores, consejos estudiantiles, consejos campesinos, para ir conformando un verdadero poder popular, que debe irse plasmando luego en las comunas.

\section{Un alto grado de descentralización que permita un real protagonismo popular}

La participación no es solamente proponer ideas y soluciones o, es fundamentalmente tomar decisiones y controlar su ejecución. El protagonismo popular se transforma en una mera consigna si la gente no tiene la posibilidad de pronunciarse y tomar decisiones en los espacios donde participa (territoriales, centros de trabajo, centro de estudio, grupos de interés). Si el Estado central es el que decide todo, no hay cabida para las iniciativas locales y ese Estado termina por ser un freno, es decir — como afirma Marx-, entorpece el «libre movimiento» de la sociedad.

Es interesante observar que el filósofo húngaro Itsván Mészáros considera que fue un exceso de centralización en el Estado soviético lo que determinó que «tanto los gobiernos como los consejos de de fábrica quedaran desprovistos de todo poder efectivo» (Mészáros, 1995: 1046) $\cdot{ }^{10}$ No es extraño, entonces, que este autor se plantee como uno de los objetivos a alcanzar en el periodo de transición «una autonomía y descentralización genuina de los poderes de toma de decisiones», al contrario de lo que ocurre actual-

10 Según Meszáros, las referencias positivas que Lenin hizo en El Estado y la Revolución «a la Comuna de París (como la participación directa de todos los sectores empobrecidos y explotados de la población en el ejercicio del poder) desaparecieron de sus discursos y sus escritos y se puso el acento sobre la necesidad de una autoridad central» y agrega: «El ideal de la acción autónoma de la clase trabajadora había sido reemplazado por la defensa de la "mayor centralización possible"» (Meszáros, 1995: 1044). 
mente donde la «concentración y centralización» necesariamente produce «burocracia» (Mészáros, 1995: 809). ${ }^{11}$

\section{La descentralización: antídoto contra el burocratismo}

La relación entre descentralización y protagonismo popular es un punto central del socialismo del siglo XXI que debemos tener muy presente; pero hay otros aspectos, como la relación entre centralización y burocratismo; claramente, no era el planteamiento de Lenin, quien relacionó siempre el fenómeno burocrático con el Estado heredado. El dirigente bolchevique murió preocupado por la «úlcera burocrática» (Lenin, 1921: 35) que afectaba al aparato estatal soviético; en uno de sus últimos textos, sostiene que es «en máximo grado una supervivencia del pasado [y que ha] sufrido en mínimo grado transformaciones sustanciales» (Lenin, 1923); días antes lo había descrito como «una mezcolanza burguesa y zarista» (Lenin, 1922: 485).

Ese diagnóstico era errado e impedía aplicar una correcta terapia a esa enfermedad. A mi entender, la causa más profunda del burocratismo -y mucho más trascendental que las herencias del pasado, que también existían - radicaba en la excesiva centralización del Estado soviético. Conocemos perfectamente lo que ocurre cuando no solamente las decisiones estratégicas sino que la mayor parte de las decisiones son adoptadas centralmente: el papeleo hacia arriba, el interminable «peloteo», la lentitud, la falta de control.

Las experiencias históricas me han ido convenciendo de que la descentralización es la mejor arma para luchar contra el burocratismo, ya que aproxima la gestión de gobierno al pueblo y permite ejercer un control social sobre el aparato de Estado. Por ello, comparto el criterio de Marx de que es necesario descentralizar todo lo que se pueda descentralizar, guardando como competencias del

11 Yo emplearía la palabra «burocratismo» en lugar de «burocracia». Textualmente dice «al contrario de su concentración y centralización existente cuyo funcionamiento sin "burocracia" resulta imposible». 
Estado central solamente aquellas tareas que no puedan ser realizadas a nivel local. En La guerra civil en Francia, Marx sostiene que «Una vez establecido el régime comunal, el antiguo gobierno centralizado tendría que dejar paso también en las provincias a la auto administración de los productores» (Marx, 1977)

Las pocas - pero importantes - funciones que quedarían para un gobierno central no se suprimirían, como se ha dicho, falseando intencionadamente la verdad. No se trataba de destruir la unidad de la nación, sino, por el contrario, de organizarla mediante un régimen comunal, convirtiéndola en una realidad al destruir el Poder del Estado, que pretendía ser la encarnación de aquella unidad, independiente y situado por encima de la nación misma, de la cual no era más que una excrescencia parasitaria.

\section{El Estado central no se debilita, se fortalece}

Por supuesto, no se trata de una descentralización anárquica. Debe existir un plan estratégico nacional articulador de los planes locales y cada uno de los espacios descentralizados debe sentirse parte del todo nacional y estar dispuesto a colaborar con recursos propios para fortalecer el desarrollo de los espacios con mayores carencias. Se trata de una descentralización que debe estar impregnada de espíritu solidario. Uno de los papeles importantes del Estado central es, justamente, realizar este proceso de redistribución de los recursos a nivel nacional para proteger a los más débiles y ayudarlos a desarrollarse.

Luego de lo expuesto, debe quedar claro que no estoy hablando de la descentralización impulsada por el neoliberalismo que, adfirma Chávez, es una estrategia mundial para debilitar la unidad nacional y el Estado nacional; lo que defiendo es otra concepción de descentralización: una concepción socialista, aquella que está plasmada en numerosos artículos de la Constitución Bolivariana, ${ }^{12}$ que, por el contrario, al fortalecer a las comunidades, a las comunas, que son los cimientos del Estado nacional, contribuye de hecho

12 Artículos 16, 157, 158, 185, 269. 
a la profundización de la democracia y al fortalecimiento del Estado central, instrumento fundamental para defender nuestra soberanía y conducir al país hacia la nueva sociedad que queremos construir. ${ }^{13}$

\section{PROPUESTA PARA AMPLIAR Y PROFUNDIZAR LA DEMOCRIACIA}

\section{Redes de democracia directa nacional}

El investigador boliviano Luis Tapia tiene una interesante propuesta que cualificaría aún más la participación política del pueblo, profundizando la democracia:

participar en la vida política tiene como una primera connotación fuerte, el estar presente en espacios políticos públicos para deliberar sobre cuestiones de interés general y dirigidas a discutir la dirección de las cosas que debería tomar el gobierno de la colectividad a la que pertenecemos, tanto a nivel local, regional y nacional (...) en este sentido, la primera tarea es pensar los espacios de la participación antes de pensar las formas de representación (Tapia, 2007: 128).

Históricamente han existido en Bolivia dos grandes espacios y formas de participación política.

Uno de ellos es el espacio comunitario, es decir, el espacio de las comunidades en las que hay especies de autogobierno que muchas veces entran en conflicto con el estado boliviano. El otro espacio es el de la social civil, es decir, el de las diferentes organizaciones de la sociedad que generalmente reflejan intereses sectoriales (Tapia, 2007: 129).

Luis Tapia propone una interesante idea: la «red de asambleas locales de democracia directa nacional». ${ }^{14}$ Se trataría de «tener espacios

13 Sobre este tema, ver Harnecker (2008).

14 Lo que a continuación exponemos ha sido desarrollado en Tapia (2007: 132137 y $180-182$ ). 
políticos de participación directa, no sólo sobre los temas locales y municipales, sino sobre los temas nacionales o plurinacionales». Considera que las personas que nacieron o eligieron vivir en lugares apartados de la capital no deben estar limitadas a discutir solamente los temas locales, deben tener también la posibilidad de participar en la discusión de temas nacionales. Ello implica organizar espacios locales de democracia directa, pero destinados a discutir los temas nacionales. Tapia piensa en una idea complementaria:

pensar la necesidad de que la agenda de los debates parlamentarios (...) sea pública y, por lo tanto, una vez que esté formulada, también sea el objeto de discusión en cada uno de esos espacios asambleísticos, que a su vez también irían alimentando con sugerencias [los] siguientes ciclos de discusión en el mismo parlamento y al conjunto de las asambleas a nivel nacional (Tapia, 2007: 134).

No serían los gobiernos locales, sino el gobierno central quien debería organizar estos espacios asambleísticos de deliberación sobre temas nacionales en todo el país. «Este nivel de las "asambleas locales democracia nacional" — como las denomina Tapiaserían el espacio en que las ciudadanas y los ciudadanos podrían ejercer, de manera continua, su derecho a la participación en el gobierno del país».

Para materializar esta idea, el gobierno debería formular un plan de discusión de los temas centrales de dirección de la política del país y establecer un cronograma de trabajo de tal manera que permita la participación en la discusión en esos espacios asambleísticos antes de pasar a la ejecución de sus políticas.

Según Tapia, este conjunto de espacios democráticos, de democracia directa, deberían tener una representación directa en el parlamento nacional multicultural y el poder ejecutivo.

En este sentido, un rasgo central de la propuesta es que la principal forma de descentralización política es la organización de esta red de asambleas de democracia nacional y multicultural en las que los ciudadanos participen en su territorio de la discusión de los temas nacionales de 
manera regular y a través de un conjunto de instituciones que permitan la comunicación y vuelta entre ambos niveles. En este sentido, la principal forma de descentralización política sería esta organización de espacios políticos donde se puede hacer política nacional en lo local./ El tamaño de las asambleas podría corresponder a nivel de los barrios en el caso de las ciudades o, alternativamente, al distrito municipal - aunque no es la tarea municipal. En todo caso habría que dejar abierta la posibilidad de que sea la misma gente la que acabe diseñar las fronteras de los espacios políticos en los que de hecho ya como parte en interacciones políticas y, por lo tanto tendrían que ser los ámbitos y el horizonte en el que se continúe en deliberando y discutiendo sobre gobierno al país./ La idea es que este nivel no se burocratice. Se necesita que haya una infraestructura y un equipo mínimo que haga que estas asambleas funcionen cada mes, y que sea la misma asamblea la que de manera rotativa elija a los representantes que lleven las decisiones de cada proceso o cada momento asambleístico a los niveles de articulación nacional, es decir, directamente al parlamento boliviano. Esto implica que no se convierten en un nivel de profesionalización de la política; tampoco tendría un costo en términos de ser un trabajo político, pero sí tendría un costo en términos de condiciones materiales para que sea posible la transmisión, en los dos sentidos de ida y vuelta. En algunos momentos, incluso la representación de los mismos en la sede del parlamento (Tapia, 2007: 181).

\section{Las comunas}

En Venezuela, el presidente Chávez ha planteado la necesidad de avanzar de los consejos comunales a la formación de lo que él ha denominado «comunas». Inspirada en sus innumerables intervenciones públicas y revisando experiencias históricas, he llegado a formular algunas ideas sobre este tema que han sido reunidas en el libro De los consejos comunales a las comunas (Harnecker, 2009). Aquí reproduciré algunas de ellas. 


\section{Un territorio compuesto por varias comunidades}

La comuna sería un territorio poblado en el que coexisten varias comunidades que comparten tradiciones histórico-culturales, problemas, aspiraciones y vocación económica comunes, que usan los mismos servicios, que tiene condiciones de autosustentabilidad y autogobernabilidad y cuyas comunidades están dispuestas a articularse en un proyecto común construido en forma participativa y constantemente evaluado y readecuado a las nuevas circunstancias que se van creando.

Los límites de este territorio, por lo tanto, no pueden fijarse considerando el número de población, como suele hacerse en los distritos electorales; tampoco pueden definirse porque existe una afinidad entre algunos dirigentes o mejores relaciones entre algunas comunidades en relación a otras y esas comunidades decidieron mancomunarse; menos puede definirse en forma arbitraria decretándolos desde arriba sin consultar con la población.

\section{Criterios objetivos para definir sus límites}

Los límites de una comuna deben definirse usando criterios objetivos, como los señalados más arriba, que aquí sintetizamos: a) tradiciones histórico-culturales communes; b) problemas y aspiraciones compartidas; $c$ ) uso de los mismos servicios, como escuelas, liceos, aldeas universitarias, centro de atención médica, instalaciones deportivas, centros culturales, mercados, cines, y otros; d) condiciones de autosustentabilidad; $e$ ) condiciones para avanzar hacia el auto gobierno; $f$ ) disposición de las comunidades a articularse en un proyecto común.

\section{Autosustentabilidad económica con orientación socialista}

La comuna debe llegar a ser autosustentable; debe ir logrando disponer de fondos propios que la hagan depender cada vez menos de recursos externos y, para ello, en su territorio deberían 
realizarse actividades productivas que le permitan obtener una parte importante de los recursos para satisfacer sus propias necesidades y sufragar sus gastos.

Cada comuna debería encaminarse a la construcción de un sistema comunal de producción y de consumo con la participación de las comunidades, a través de las organizaciones comunitarias, cooperativas, empresas de propiedad social con orientación socialista, procesos de intercambio no mercantil y muchas otras formas innovadoras que conduzcan a la creación de ese nuevo modelo productivo, como expresión del poder y control popular sobre la producción.

Lo lógico es que uno de los ejes estructurantes clave de la comuna sean las unidades de producción o servicios de propiedad comunal o estatal comunal. Si se trata de una comuna rural, podría combinarse la existencia de cooperativas agrarias para el cultivo de determinas frutas y hortalizas, la compra de estos productos para su procesamiento industrial por una empresa de propiedad social comunal y la distribución de los productos elaborados en ella en tiendas populares de orientación socialista de la comuna y fuera de ella.

Por otra parte, además del banco de la comunam (del que se hablará más adelante), podrían existir otras iniciativas de financiamiento como las cajas rurales, las cooperativas de ahorro y préstamo y las cajas de ahorro.

\section{Empresas de propiedad social communal}

Deberían instalarse en cada comuna empresas de propiedad comunal que empleen mano de obra de ese territorio y produzcan bienes y servicios para disfrute o uso comunal: panadería, mercado, empresa de transporte comunal, empresa que regule la distribución del agua y su cobro, una planta de llenado de bombonas de gas licuado y estación de servicios, entre otras. Para determinar estas actividades, es muy importante realizar un proceso de planificación participativa que lleve a formular el Plan de Desarrollo de 
la comuna según las características, necesidades e intereses de las comunidades, para crear bienes y servicios mediante un sistema de articulación entre las actividades del sector primario, la transformación de estas u otras materias primas y la comercialización de la producción a fin de generar excedentes.

Las iniciativas generadoras de empleo deberían ser apoyadas centralmente durante su etapa de despegue hasta que lleguen a ser autosustentables financieramente.

\section{Gobierno comunal}

Por otra parte, se debe ir avanzando hacia el establecimiento del autogobierno comunal. El municipio debería ir transfiriendo a las comunas una parte importante de las funciones de gobierno y de manejo de los asuntos públicos que anteriormente eran sus funciones. ${ }^{15}$ La alcaldía debería conservar en sus manos solamente aquellas funciones que, por su carácter más general o más complejo, justifican esa decisión.

La comuna debería asegurar las condiciones materiales y espirituales que permitan su desarrollo productivo y la satisfacción de las necesidades materiales, sociales, culturales y otras necesidades colectivas de sus habitantes y, para ello, debe trabajar y articular todos los esfuerzos en función de un plan de desarrollo comunal elaborado en forma participativa.

\section{Parlamento comunal constituido por la asamblea del poder popular de la comuna}

En cada comuna debería constituirse un parlamento comunal o poder legislativo comunal, que sería la instancia de toma de decisiones de los habitantes de la comuna, quienes podrían llamarse «comuneras»y «comuneros». Este parlamento estaría compuesto

15 Ver Art.184 de la Constitución y artículos 60, 61 y 70 de la Ley orgánica del poder público municipal. 
por voceras y voceros de los diferentes consejos comunales, de los consejos de trabajadores y de los consejos temáticos o grupos de interés, situados en su territorio y dispuestos a participar en la construcción de la comuna y no sería otra cosa que la asamblea del poder popular de la comuna.

Para expresar y hacer más expedito el trabajo de estas voceras y voceros se propone crear un equipo de asesoría jurídica a ese parlamento y reunirlos en tres cuerpos colegiados: un consejo del poder popular de comunidades; un consejo del poder popular de trabajadores y un consejo del poder popular temático. Cada uno de estos consejos del poder popular trabajaría en forma separada sus temas específicos y se reunirían en una gran asamblea del poder popular de la comuna para discutir los temas comunes y hacer las articulaciones necesarias. La asamblea del poder popular de la comuna sería la máxima instancia de poder popular en ese territorio.

Asambleas del poder popular conforman sus respectivos órganos de gobierno

La comuna debería ser capaz de asumir una serie de actividades que hasta ahora han sido competencia del municipio, como el cobro de impuestos, el aseo comunal, el cobro y el mantenimiento del servicio eléctrico, el agua potable y la vialidad local, el mantenimiento de los locales públicos comunales; para ello, deberá crear un aparato que le permita ejercer estas responsabilidades.

En el futuro, debería ser la asamblea del poder popular la que estableciera el gobierno de la comuna, constituyendo los aparatos o instancias que le permitan asumir las tareas que derivan de las competencias que le han sido transferidas. Sería esta asamblea la que debería elegir a las personas que ocuparían cargos en cada uno de los restantes cuatro poderes reconocidos por la constitución bolivariana: el ejecutivo, el judicial, el moral y el electoral. Estos servidores públicos deberían rendir cuentas y podrían ser revocados si se considera que no están cumpliendo con el mandato para el cual fueron electos. 


\section{Consejo de planificación comunal y sala técnica}

La comuna debe contar con un consejo de planificación comunal que debe impulsar en cada inicio de peroodo de gobierno un proceso de planificación participativa para elaborar el plan plurianual de desarrollo estratégico y los planes anuales, que deben estar insertos en el plan de desarrollo estratégico de la nación, y el resto de los planes locales, y que, a su vez, debe nutrir estos planes con sus propuestas y proyectos.

Llamamos «consejos temáticos» a las voceras y los voceros de las organizaciones que se agrupan en torno de una línea de interés o temática; por ejemplo, organizaciones de mujeres, de estudiantes, de la juventud, de la tercera edad, de las personas con discapacidad; grupos en defensa del medio ambiente, contra la discriminación racial y cuestiones de género; organizaciones que agrupan a personas en torno de temas como salud, educación, deportes, cultura y muchos otros.

\section{Banco de la comuna}

La comuna debería contar también con una entidad financiera o banco de la comuna donde se reciban todos los fondos que ella debe administrar.

El Estado nacional debería garantizar un fondo destinado a un despegue de las comunas que se rija por un principio de equidad solidaria. Las comunas más carentes y menos atendidas históricamente por el Estado deberían recibir más fondos que las demás

Mientras se crea el banco de la comuna, nadie puede impedir que se mancomunen los fondos de todos los consejos comunales pertenecientes a la comuna en un proyecto único, asumiendo cada consejo, desde el punto de vista financiero, una parte del proyecto, oque se elija uno de los bancos ya constituidos de un consejo comunal para recibir los fondos de alguna institución del estado dispuesta a apoyar algún proyecto de la comuna. La disposición de los consejos comunales a compartir sus recursos con todos los 
consejos comunales es un buen índice de que están madurando las condiciones subjetivas para avanzar hacia el autogobierno.

\section{Control social sobre el gobierno}

Debería existir un eficiente control social sobre el funcionamiento del gobierno facilitando vías y mecanismos que permitan que los ciudadanos y las ciudadanas organizados puedan pronunciarse ante la calidad de los servicios y tengan potestad de promover la destitución de aquellos funcionarios cuyo desempeño haya sido cuestionado por un número suficiente de ciudadanos y ciudadanas. Debemos recordar siempre que las comunas no son solamente territorios, sino una relación entre territorio y población, y que esta población debe participar en forma activa tanto en la delimitación del territorio como en la construcción del gobierno comunal.

\section{No se pueden decretar desde arriba}

Por eso las comunas no se pueden decretar desde arriba. No son los gobernadores ni los alcaldes los que, por decisión propia y sin un estudio territorial previo, deben conformar comunas. No se trata de luchar para saver quién tiene más comunas. Tampoco se deben crear comunas en forma artificial solamente para obtener recursos del Estado. No se debe forzar el proceso de maduración subjetiva de quienes habitan en esos territorios. Los equipos de las gobernaciones y alcaldías deben ser facilitadores del proceso y no suplantadores de lo que la gente debe hacer por sí misma.

\section{Experimentar funcionamiento diferente del aparato estatal} heredado

Las experiencias de las comunas deberían servir también para experimentar en ellas un funcionamiento diferente del aparato del Estado poniéndolo a su servicio; en ellas, las instituciones del Estado deberían trabajar en forma armónica, al servicio de los 
intereses de la respectiva comuna y, para ello, deberían, por una parte, articularse entre ellas y, por otra, reunirse con la vocería comunitaria para seguir sus lineamientos basados en el plan comunal. Sus actuaciones deberían someterse a la contraloría social comunal $\mathrm{y}$, en caso de que algún funcionario «no diera la talla» para cumplir esta función de articulación y servicio, debería de haber un compromiso de cada institución a nivel nacional o local para cambiar a ese funcionario.

Conclusión: una descentralización que fortalece el Estado central

El proceso de construcción de las comunas implica llevar adelante un proceso de descentralización de competencias y recursos en forma planificada e inserta en el plan nacional de desarrollo que favorezca el protagonismo popular, que permita que el sujeto revolucionario madure aprendiendo a través de la práctica y, al hacerlo, en lugar de debilitar el estado central lo haga más fuerte.

\section{CONCLUSIÓN}

Luego de haber planteado algunas reflexiones generales acerca de la relación entre democracia y socialismo, y de terminar con algunas propuestas de cómo seguir avanzando hacia el autogobierno del pueblo que caracteriza a una sociedad socialista, podemos concluir que el sistema democrático será más fuerte en la medida en que sus cimientos sean más sólidos. Estos cimientos no son sino los diversos espacios de participación en las bases mismas de la sociedad donde el pueblo puede verdaderamente ejercer el gobierno. De ahí que no podamos hablar de democracia verdadera sin socialismo, ni de socialismo sin plena democracia. 


\section{REFERENCIAS}

Chávez, Hugo (2005), Discurso en la IV Cumbre de la Deuda Social, 25 de febrero.

(2006), Discurso de la unidad, Caracas, Ediciones socialismo del Siglo XXI, No.1, Caracas, 15 de diciembre.

(2009), Intervención en programa radio-televisivo Primer Aló Presidente teórico, 11 de junio.

Сномsкy, Noam (1996), El control de los medios de comunicación, en Cómo nos venden la moto, Barcelona, Icaria.

GARCíA, Álvaro (2007), «Estado plurinacional» en Álvaro García Linera, Luis Tapia Mealla y Raúl Prada Alcoresa, La transformación pluralista del Estado, La Paz, Muela del diablo editores/Comuna.

GARCíA, Álvaro (2010), Intervención en el programa «El pueblo es noticia», Canal 7 y Radio Patria Nueva, 8 de febrero.

HARNECKER, Marta (1994), Haciendo camino al andar. Experiencias de ocho gobiernos locales de América Latina, Santiago de Chile, Lom.

(coord.) (2008), La descentralización ifortalece o debilita el Estado nacional?, libro que recoge las intervenciones de los participantes en el taller del 23 y 24 septiembre 2008, www.rebelion.org/docs/85465.pdf. (2009), «De los consejos comunales a las comunas. Construyendo el socialismo del siglo XXI» en: www.rebelion.org/docs/83276.pdf.

LeBowitz, Michael (2006), Construyámoslo ahora. El socialismo para el siglo XX, Caracas, Centro Internacional Miranda.

(2008), El camino del desarrollo humano ¿Capitalismo o socialis$m o$ ?, Caracas, Centro Internacional Miranda.

LENIN, ¿Qué debemos hacer con la inspección obrera y campesina? (9 de enero de 1923), Obras completas, tomo 36.

LENIN, (1921) X Congreso del PC (b) R, en Obras completas, tomo 35.

(1980), El marxismo y el Estado, Moscú, Progreso.

(1922), El problema de las nacionalidades de la «autonomización» Obras completas, t. 36.

LEY del poder público municipal

MANEIRo, Alfredo (1977), Escrito con la izquierda, entrevista realizada por Iván Loscher, en Alfredo Maneiro, Escritos de Filosofía y política, Caracas, Estado Miranda. 
MARX, Carlos (1977), La guerra civil en Francia. Obras escogidas, Moscú, Progreso.

MeszÁros, István (1995), Más allá del capital, Caracas, Vadell Hnos.

Asamblea Nacional Constituyente (1999), Nueva Constitución de la República Bolivariana de Venezuela, Capítulo IV: De los derechos Políticos y del Referendo Popular, Sección Primera: de los derechos políticos. Gaceta Oficial, 1999, Caracas, 30 de diciembre.

TAPIA, Luis (2007), «Gobierno multicultural y democracia directa nacional» en Álvaro García Linera, Luis Tapia Mealla y Raúl Prada Alcoresa, $L a$ transformación pluralista del Estado, La Paz, Muela del diablo/Comuna.

ToussAint, Eric (2009), La roue de l'histoire tourney au Venezuela,en Equateur et en Bolivie.

ZECEVIC, Miodrag (1977), El sistema de delegados, 1977.

(2007), El sistema político yugoslavo. Buscando un camino alternativo al sistema representativo burgués y al sistema estatista soviético, (Selección de textos de Marta Harnecker), Caracas, Centro Internacional Miranda. 